\title{
TRADUÇÃO, VIAGEM, LITERATURA: (RE)ESCREVENDO E COLONIZANDO UMA CULTURA
}

\section{Eduardo Luis Araújo de Oliveira Batista}

\section{Introdução}

Neste artigo apresentamos um breve levantamento de como o trabalho dos viajantes, tradutores e acadêmicos vem construindo ao longo do tempo uma imagem do Brasil vinculada diretamente aos interesses das naçôes colonizadoras como justificativa de seu domínio sobre o país (colonial, econômico e cultural), partindo da relação estreita entre tradução, literatura e identidade cultural. Demonstramos como a estratégia da descrição e da tradução como discurso de dominação encontra-se presente desde a produção do primeiro documento escrito sobre o país, a Carta de Caminha, e como esse discurso de dominação apresenta-se de forma recorrente no trabalho catequizador dos missionários jesuítas no Brasil colônia e na descrição dos viajantes do século XIX, relacionando-o ainda à questão da discussão de uma poética literária nacional que se inicia no começo do século XIX com a independência política e repercute contemporaneamente nos estudos literários comparatistas internacionais.

A história cultural brasileira, marcada pelo colonialismo europeu, desenvolveu-se em boa parte através da ação dos viajantes e dos tradutores, negociando imagens entre a colônia que se emancipa e se constitui em uma nova nação e entre seus diversos interlocutores do Velho e Novo Mundo. Longe de estabelecerem um diálogo equânime, as relaçõos interculturais, notadamente nas formas da literatura de viagem e da tradução aqui estudadas, têm sido marcadas pelas relaçôes de poder, resultando muitas vezes em verdadeiros atos encobertos de dominação sobre a cultura descrita/ traduzida. Esse discurso de dominação pode se concretizar através da manipulação e disseminação de imagens dessas culturas onde os critérios políticos se sobressaem aos estéticos ou científicos. Essa, por exemplo, é a tese apresentada por Edward Said em Orientalismo, onde o autor demonstra como, através dos tempos, o Ocidente foi construindo uma imagem do Oriente através dos escritores, tradutores, estudiosos, viajantes, artistas, etc., apagando as histórias locais e divulgando uma imagem diretamente vinculada aos inte- 
resses imperialistas das nações europeias. Nas palavras do próprio Said, "o orientalismo pode ser discutido e analisado como a instituição organizada para negociar com o Oriente - negociar com ele fazendo declarações a seu respeito, autorizando opiniōes sobre ele, descrevendo-o, colonizando-o, governando-o". . Se o orientalismo, de acordo com o ponto de vista de Said, empenhou-se em apagar e reescrever as histórias do Oriente como estratégia colonizadora valendo-se das práticas da literatura de viagem e da tradução, entre outras, no caso do Brasil tratou-se antes de tudo de construir essa história, já que aqui não havia civilizações antigas e desenvolvidas como as do Oriente, ou mesmo as encontradas em outras regiōes da América, como nos Andes e na América Central, que oferecessem registros escritos de suas próprias histórias.

No decorrer da história brasileira, até praticamente o final do século XIX, a maior parte do conhecimento sobre o Brasil foi construída principalmente pelos viajantes estrangeiros que percorreram, registraram e descreveram o território e seus povos através de seus textos e imagens. Esses diversos viajantes sobrepuseram suas diferentes versões do Brasil, que, no entanto, apresentam como elemento recorrente a exuberância da natureza (já encontrada na Carta de Caminha) como tema principal na definição de um caráter identitário do país. O interesse dos europeus pelo conhecimento do Brasil e suas potencialidades gerou uma extensa bibliografia, que, se começou a ser construída pelos viajantes, a partir das primeiras décadas do século XX, vai se especializar no trabalho dos etnógrafos e posteriormente no dos brasilianistas, estudiosos estrangeiros de diversas áreas das ciências humanas que se especializam no Brasil. Essa extensa bibliografia pode ser enquadrada no que José Antônio Segatto chama de "historiografia do imperialismo", e vai refletir os interesses e as perspectivas das diferentes nações com as quais o Brasil se relacionou, especialmente as europeias e a estadunidense, que se definiram ao longo da história brasileira como seus principais interlocutores culturais.

\section{Traduzindo e colonizando o Brasil}

A conjunção entre tradução e relato de viagem como estratégia colonizadora já se encontra presente de forma clara na Carta de Caminha. Além de descrição da terra descoberta e dos índios que a habitavam, originando uma imagem que vai se propagar através dos séculos, a Carta também nos apresenta as primeiras dificulda-
*(SAID, Edward. Orientalismo. O Oriente como invenção do Ocidente. Trad. Tomás Rosa Bueno. São Paulo: Companhia das Letras, 1990:15.)

* (SEGATTO, José Antonio. "Algumas notas sobre a historiografia do imperialismo". Cadernos de Pesquisa. São Paulo: Brasiliense, 1978.) 
- CAMINHA, Pero Vaz de. Carta. In: MEDONÇA, Manuela; VENTURA, Margarida G. (eds.). Mar de letras. Lisboa: [s.e.], 1999. p.5875: 63.)

(Ibidem: 66.)

(Ibidem: 72.) des trazidas pelo desconhecimento linguístico mútuo entre os europeus e os nativos, e as estratégias buscadas para enfrentar a situação. Percebendo a impossibilidade de entendimento da língua dos indígenas, a primeira preocupação do capitão da expedição é enviar um degredado para se introduzir entre os índios e trazer informações. Segundo Caminha, o capitão "mandou com eles (os índios), para lá ficar, um mancebo degredado, criado de D. João Telo, a que chamam Afonso Ribeiro, para lá andar com eles e saber de seu viver e maneira". Afonso Ribeiro pode ser considerado como o primeiro intérprete ou mediador cultural entre os habitantes da terra que seria chamada de Brasil e a Europa. Mas sua introdução entre os indígenas sofrerá a resistência dos mesmos, que, desconfiados, o devolvem repetidas vezes aos navios portugueses. $\mathrm{O}$ capitão pensa então em levar para a Europa alguns índios à força para servirem de informantes, mas é dissuadido a deixar mais dois degredados para se infiltrarem entre os nativos, estratégia que se tornará recorrente no período colonial:

E tanto que a conclusão foi tomada, perguntou mais se seria bom tomar aqui por força um par destes homens para os mandar a Vossa Alteza, e deixar aqui por eles outros dois destes degredados. Quanto a isso acordaram que não era necessário tomar por força homens, porque era geral costume dos que assim levavam à força para alguma parte dizerem que ali há tudo o que lhe perguntam, e que melhor e muito melhor informação da terra dariam dois homens destes degredados que aqui deixassem, do que eles dariam se os levassem, por ser gente que ninguém entende. [...] E que, portanto, não cuidassem de tomar ninguém nem fazer escândalo, para de todos mais os amansar e apacificar (sic) $[\ldots]^{*}$

A estratégia da substituição do rapto dos indígenas pela infiltração de mais dois degredados, apesar de aparentar uma atitude mais pacífica, não chega a encobrir os verdadeiros interesses de domínio sobre os nativos desejado pelos portugueses, e reforça a ação estratégica dos intérpretes na persecução desse objetivo:

E, portanto, se os degredados, que aqui hão de ficar, aprenderem bem sua fala e os entenderem, não duvido que eles, segundo a santa intenção de Vossa Alteza se hão de fazer cristãos e crerem em nossa santa fé, a qual praza a Nosso Senhor que os traga, porque, certo, esta gente é boa e de boa simplicidade, e imprimir-se-á ligeiramente neles qualquer cunho que thes quiserem dar.

Nesta declaração o projeto colonialista fica explícito, encoberto pelo discurso religioso. Ao apresentar os índios como uma folha 
em branco, como um povo sem cultura, sobre o qual se imprimirá facilmente a marca da civilização europeia, Caminha transforma os nativos no objeto ideal do empreendimento colonialista europeu. E ele completa:

segundo o que a mim e a todos pareceu, esta gente não lhe falece outra cousa para ser cristã senão entender-nos. [...] E para isso, se alguém vier, não deixe logo de vir clérigo para os baptizar, porque já então terão mais conhecimento de nossa santa fé pelos dois degredados que aqui entre eles ficam [...].

Conhecer a língua e as maneiras dos índios e divulgar as ideias europeias entre eles - essas, segundo a declaração de Caminha, eram as principais tarefas dos línguas - forma como os degredados e outros europeus deixados na colônia para viverem com os índios eram chamados.

Essas tarefas e conselhos sobre como civilizar os indígenas, expressos por Caminha em sua carta, serão levados a cabo com fervor pelos jesuítas, que chegaram ao Brasil em 1549 e implantaram seu projeto missionário que se baseava principalmente no desenvolvimento do conhecimento linguístico da cultura indígena e em um processo de tradução - linguística e cultural - que ajudou a impor os preceitos da cultura europeia sobre os nativos e apagar suas próprias origens culturais.

Como coloca Paula Montero* a respeito dos contatos que se estabeleceram entre os jesuítas e índios a partir de sua chegada à colônia, a "ideia de que esses 'encontros' são feitos de violência e desigualdade de forças" é um ponto de partida, e não uma conclusão. Essa violência, como foi mencionado, dá-se através do apagamento da tradição cultural, colonizada através da sua reescrita. Segundo Montero,

o modus operandi da atividade missionária em geral é sua valorização da inscrição do outro: seja através da gramaticalização das línguas, da produção/tradução dos catecismos, seja através da descrição dos modos de ser e pensar indígenas, a atividade da escrita para e sobre os nativos fixa os acontecimentos em narrativas que vão, progressivamente, depositando significações.

Junto às descrições dos nativos e de sua forma de viver, que justificam a abordagem civilizatória dos europeus (através de sua caracterização como um povo sem lei, rei, ou fé), a estratégia tradutória também se impôs como recurso de dominação no trabalho missionário dos jesuítas. Segundo Montero, através de um proces-
(Ibidem: 74.)

" (MONTERO, Paula (org.) Deus na aldeia. Missionários, índios e mediação cultural. São Paulo: Globo, 2006: 24.)

(Ibidem: 59.) 
- (AGNOLIN, Adone. “Catequese e tradução: gramática cultural, religiosa e linguística do encontro catequético e ritual nos séculos XVIXVII". In: MONTERO, Paula. (org.) Deus na aldeia. Missionários, índios e mediação cultural. São Paulo: Globo, 2006. p.143-208: 161.)

( (LEITE, Ilka Boaventura. Antropologia da viagem. Belo Horizonte: UFMG, 1996: 40) so de tradução cultural, baseado no discurso religioso, os missionários vão estabelecer uma pedagogia jesuítica que vai se utilizar de elementos já existentes na cultura nativa como linguagem para veicular conteúdos da fé católica, inscrevendo sobre o elemento cultural indígena o elemento europeu, apagando-o e substituindo-o num processo de sobreposição onde o Tupã torna-se o Deus católico, e Tupansy, mãe de Tupã, torna-se Nossa Senhora. ${ }^{*}$ Mais do que a simples divulgação dos textos sagrados católicos na língua entendida pelos índios, o processo de gramaticalização da língua indígena pelos jesuítas, e sua sistematização na língua geral, a partir do tupi e do guarani, que passou a ser adotada pela maioria das etnias em contato com os brancos, por sua vez, teria sido parte de um processo para estabelecer uma "unidade normativa, linguística e cultural indígena, para fundar uma possibilidade interpretativa jesuítica (ocidental)" no entender de Adone Agnolin. ${ }^{*}$ Como diz ainda Montero, os textos religiosos traduzidos e escritos na língua geral, os catecismos, vocabulários e artes gramáticas, mais do que traduzir palavras, traduziam tradições. É nesse sentido que converter passa a significar traduzir.

Relatos de viagem e a natureza como identidade brasileira

Se o projeto missionário jesuítico e sua estratégia linguística e tradutória de "inscrição do outro", segundo termo de Montero, são desbaratados após cerca de dois séculos de atuação, com a intervenção do Marquês de Pombal, que expulsou os jesuítas do território e extinguiu as famosas Missóes, o processo de inscrição do outro continuou a se estabelecer através da literatura de viagem. Reprimida pela proibição da entrada de estrangeiros no território colonial, proibição que se intensificou com as descobertas de ouro e diamante nas Minas Gerais a partir do fim do século XVII, a literatura de viagem sobre o Brasil ganha novo alento com a abertura dos portos em 1808, possibilitando uma verdadeira invasão do território por um enorme contingente de viajantes de diversas partes do mundo prontos a descreverem e divulgarem as potencialidades do país.

Esse corpus de relatos de viajantes vai criar e difundir boa parte das representações sobre o Brasil, especialmente do século XIX, representaçōes que, segundo Ilka Boaventura Leite, em sua maior parte revelam "[...] um conteúdo comprometido com uma visão colonialista e etnocêntrica" europeia, "visão que terá suas repercussões também na literatura nacional então em formação. $\mathrm{O}$ inau- 
gurador desse novo ciclo de representaçōes sobre o Brasil foi o alemão Alexander von Humboldt, que, curiosamente, não esteve no Brasil, proibido pela Coroa Portuguesa de entrar no território colonial. Apesar disso, segundo Mary Louise Pratt, Humboldt, que percorreu diversas regiões da América do Sul a partir de 1799, e publicou suas viagens nos famosos Tableaux de la nature, a partir de 1808, foi o responsável por estabelecer as linhas para a reinvenção ideológica da América do Sul que teve lugar em ambos os lados do Atlântico durante as primeiras décadas do século XIX.* Através de seus textos, mapas e desenhos, Humboldt caracterizou um território que até então se apresentava como um mapa em branco para o norte europeu. Para Pratt, Humboldt reinventou a América antes de tudo como natureza. Segundo ela, não a natureza classificável e colecionável de Lineus, mas "uma natureza dramática, extraordinária, um espetáculo capaz de oprimir o conhecimento e entendimento humano" $1^{*}$ Ou seja, uma representação da natureza já muito mais comprometida com uma visão romântica do que neoclássica. Segundo Pratt, uma característica dos textos de Humboldt sobre a América do Sul é a ausência do elemento humano. Para a autora, continuando a tradição estabelecida por Colombo e Vespúcio, Humboldt "escreveu a América como um mundo primitivo da natureza, um espaço atemporal e não reclamado, ocupado por plantas e criaturas (algumas delas humanas), mas não organizado por sociedades de economias; um mundo cuja única história estava para ser começada" $2^{*}$ - história a ser começada pelos europeus que traziam a civilização para uma terra de ninguém. Se tal ponto de vista, de uma natureza exuberante que sobrepuja a presença humana nativa, podia ser aceito para a América espanhola, mais fácil ainda seria estendê-la à América portuguesa, habitada por índios em estado muito inferior de desenvolvimento material do que seus vizinhos. A representação da América do Sul como natureza, despojada da presença humana, oferecia um território virgem para o empreendimento europeu. A influência de Humboldt chegaria ao Brasil não apenas como referência científica e ideológica dos diversos naturalistas e estudiosos europeus que percorreram e des-

\footnotetext{
${ }^{1}$ No original: "a dramatic, extraordinary nature, a spectable capable of overwhelming human knowledge and understanding” (esta e outras citaçōes foram traduzidas pelo autor deste artigo).

2 "wrote America as a primal world of nature, an unclaimed and timeless space occupied by plants and creatures (some of them human), but not organized by societies and economies; a world whose only history was the one about to begin".
}

* (PRATT, Marie-Louise. Imperial eyes: travel writing and transculturation. London and New York: Routledge, 1992: 111.)

(Ibidem: 120.)

(lbidem: 120.) 
- (ROUANET, Maria Helena. Eternamente em berço esplêndido. A fundação de uma literatura nacional. São Paulo: Siciliano, 1991.)

(Ibidem: 90.)

(Ibidem: 94.) creveram o país durante o século XIX, mas também mediada pela atuação do francês Ferdinand Denis, que teria se inspirado em Humboldt e sua valorização do poder de influência do clima, do solo e da natureza sobre as artes, em sua proposta poética para a literatura brasileira.

\section{Discurso literário e olhar estrangeiro}

Em seu Resumo da história literária brasileira, de 1826, Ferdinand Denis não apenas inaugura a historiografia literária brasileira, mas propõe uma poética, baseada na descrição da natureza tropical e dos costumes tradicionais como modelo pedagógico a ser seguido pelos escritores brasileiros românticos interessados em fundar uma literatura nacional para o país recém-independente. Denis impôs uma imagem do Brasil que deveria ser representada pelos escritores brasileiros em suas obras, imagem baseada na valorização do pitoresco e do exótico segundo o olhar do viajante europeu. Sua proposta foi incorporada na literatura e desenvolveu uma tradição nacionalista que iria definir por um longo período os rumos da produção crítica e literária brasileira, como demonstra Maria Helena Rouanet. ${ }^{*}$ Para Rouanet, a obra de Denis enquadrou-se no discurso pedagógico desenvolvido pela França sobre a América, especialmente o Brasil, a partir do século XIX, como uma estratégia colonial. Segundo a autora, a presença da estratégia pedagógica intensifica-se nos textos dos viajantes franceses sobre o Brasil no decorrer do séc. XIX, "na medida em que a França perde terreno, sob este aspecto [da influência sobre o Brasil], não apenas para as demais nações europeias, mas também para a jovem nação norte-americana” * Para Rouanet, a acentuação da função colonizadora nos relatos aponta um novo caminho na disputa de influência, através da substituição da diplomacia e das invasões armadas pela "fecunda infiltração da raça e do gênio" - "ao invés do navegador normando ou do corsário [...] homens de letras, de livros, que possam incumbir-se da preconizada 'infiltração' daquela 'semente francesa". . O projeto colonizador francês seria concebido como um projeto pedagógico, e a intenção de Denis seria estender os "benefícios" do intercâmbio colonizador a um campo que estaria ressentido de sua falta, o das letras. Essa intenção pode ser entrevista no Resumé, quando Denis trata da influência francesa sobre a literatura brasileira: 
o papel que nos cabe desempenhar nesse país é ainda muito significativo, e se os ingleses têm, mais do que nós, a influência comercial que em toda a parte lhes caracteriza a atividade, devemos contentarnos com ver uma nação esplendente de juventude e de engenho afeiçoar-se às nossas produçôes literárias, por causa destas modificar suas próprias produçôes, e estreitar através dos liames espirituais os que devem existir na ordem política.

Denis pode ser considerado o maior representante dessa estratégia nesse momento. Sua obra não apenas resgatou e divulgou a nascente cultura nacional brasileira, mas ajudou a formá-la. Apesar da busca de criação de uma identidade nacional, baseada em caracteres originais e locais, essa tendência exotista fundada no olhar estrangeiro acabou limitando o espaço de atuação da literatura brasileira, como comenta Antonio Candido, reconhecendo a reprodução, na esfera cultural, de uma dinâmica colonialista socioeconômica:

[...] daí um persistente exotismo, que eivou a visão de nós mesmos até hoje, levando-nos a nos encarar como faziam os estrangeiros, propiciando, nas letras, a exploração do pitoresco no sentido europeu, como se estivéssemos obrigados a exportar produtos tropicais também no terreno da cultura espiritual.

A analogia entre a produção cultural e comercial brasileira estabelecida por Candido, apesar de que atualmente tenha perdido bastante do seu impacto, nos lembra como as relaçôes desiguais de poder, que regem as relações comerciais entre as nações, invadem a esfera literária e cultural. Apesar de que aparentemente tenhamos nos libertado da camisa de força do exotismo e do nacionalismo como critério de qualidade e originalidade literária, o que permitiu, por exemplo, o desenvolvimento do movimento concretista a partir da década de 1950, a ideia de propor espaços reservados para as literaturas segundo suas posições ocupadas no sistema econômico internacional continua a vigorar. Essa ideia pode ser encontrada no texto do teórico da literatura Fredric Jameson, "Thirdworld literature in the era of multinational capitalism", , publicado em 1986, mas que repercute ainda hoje nos meios literários. Em seu texto, Jameson propõe uma poética para a literatura produzida nos países do Terceiro Mundo, baseada em seu conceito de alegoria nacional, segundo o qual toda literatura produzida fora do Terceiro Mundo "necessariamente projeta uma dimensão política na forma da alegoria nacional: a história do destino privado individual é sempre uma alegoria da situação da sociedade e cultura
" (DENIS, Ferdinand. "Resumo da história literária do Brasil". Tradução GuiIhermino César. In: CÉSAR, Guilhermino. Historiadores e críticos do modernismo. 1. A contribuição européia: crítica e história literária. São Paulo, Edusp, 1978: 41.)

(CANDIDO, Antonio. Formação da literatura brasileira. Belo Horizonte: Itatiaia, 1997: 289.)

"JAMESON, Fredric. "Thirdworld literature in the era of multinational capitalism". Social Text, n. 15. Durham: Duke University Press, 1986: 65-68.) 
pública do Terceiro Mundo". $3^{*}$ Resumindo brevemente a ideia de Jameson, ele propõe que os textos literários do Terceiro Mundo, que se mantêm fora do cânone ocidental, deveriam ser incorporados através da criação de uma teoria que demonstrasse sua especificidade frente à literatura do Primeiro Mundo, proporcionando um espaço para sua inclusão. Como sugestão para essa teoria, ele oferece o conceito de alegoria nacional, baseando-se num paralelismo evolutivo-histórico segundo o qual os intelectuais do Terceiro-Mundo apresentariam, pelo menos naquele momento em que escreveu seu texto, um "obsessivo retorno" ao nacionalismo, algo já superado há muito tempo, segundo seu ponto de vista, pelo Primeiro Mundo. Esse atraso histórico se refletiria na literatura produzida nessas naçōes:

o romance do Terceiro Mundo não vai oferecer as satisfaçōes de Proust ou Joyce; mais danoso que isso, talvez, seja sua tendência de nos relembrar de etapas ultrapassadas de nosso próprio desenvolvimento cultural do Primeiro Mundo e nos levar a concluir que eles ainda estão

-(AHMAD, Aijaz. "A retórica da alteridade de Jameson e a 'alegoria nacional'". Trad. João Moura Jr. Novos Estudos, n. 22, São Paulo: CEBRAP, 1988: 157-181.) escrevendo novelas como Dreiser ou Sherwood Anderson. ${ }^{4^{*}}$

O texto de Jameson foi amplamente criticado e transformouse em uma polêmica nas páginas da Social Text entre seu autor e o escritor de origem indiana Aijaz Ahmad. Ahmad* criticou o olhar civilizador de Jameson, baseado no etnocentrismo que apaga as especificidades de diversas naçôes a partir de um olhar homogeneizante e que impõe uma perspectiva de fora sobre um enorme contingente de culturas, estabelecendo ainda relações diretas entre subdesenvolvimento econômico e produção cultural atrasada. Além da impropriedade de se basear num critério estritamente econômico para definir todo um conjunto de literaturas de diferentes tradiçôes, critica-se o caráter prescritivo da proposta de Jameson, que faz ecoar a proposta de Ferdinand Denis aos românticos brasileiros. Como Denis, Jameson, partindo de um olhar do centro para a periferia, busca estabelecer, de forma prescritiva, uma teoria poética que, ao mesmo tempo que procura abrir um espaço para o reconhecimento de uma literatura, a enquadra em uma camisa de força que a re-

\footnotetext{
3 "necessarely project a political dimension in the form of national allegory: the story of the private individual destiny is always an allegory of the embattled situation of the public third-world culture and society"

4 "the third world novel will not offer the satisfactions of Proust or Joyce; what is more damaging than that, perhaps, is its tendency to remind us of outmoded stages of our own first world cultural development and to cause us to conclude that they are still writing novels like Dreiser or Sherwood Anderson."
} 
duz a uma reverberação de uma teoria alienada de sua própria realidade interna. Como lembra Ahmad, "afirmar que todos os textos do Terceiro Mundo são necessariamente isso ou aquilo é afirmar, na verdade, que todo texto que se origine nesse espaço social e que não seja isso ou aquilo não é uma 'verdadeira narrativa",", ou que não é um verdadeiro texto do Terceiro Mundo.

No século XIX a adoção da estética literária proposta por Denis, baseada na descrição pitoresca, levou escritores como Machado de Assis a responderem a pesadas críticas pela ausência do "Brasil" em sua obra, obstruindo a recepção, tanto nacional quanto internacional, daquele que seria considerado o maior escritor brasileiro de todos os tempos. É célebre a polêmica surgida entre Sílvio Romero e Machado, exatamente pela suposta ausência de "brasilidade" nos romances de Assis, acostumadas estavam as mentes dos leitores brasileiros de encontrarem essa "brasilidade" de maneira gratuita e aparente nas descriçôes das florestas luxuriantes e dos índios e seus costumes exóticos. Respondendo a essas críticas e tentando oferecer um novo paradigma estético literário Machado publica seu "Instinto de Nacionalidade", onde procura demonstrar que é possível produzir uma literatura brasileira e nacionalista sem se ater às descrições de aspectos exóticos do país. Assim como enfrentou críticas no cenário cultural brasileiro, a não adesão de Machado à estética do exotismo e da descrição também o levou a enfrentar percalços em sua recepção no exterior. Para isso basta levarmos em consideração que a primeira tradução de uma obra de Assis para o inglês aconteceu somente em 1952, sessenta e seis anos após a publicação da primeira tradução de uma obra brasileira para o inglês, Iracema, de José de Alencar, em 1886. Machado não oferecia o apelo do exótico e da descrição do país que mais chamava a atenção do leitor estrangeiro. Apenas no final do século XX Machado de Assis começa a consolidar sua reputação internacional, sendo incluído por críticos como Harold Bloom entre os cem maiores gênios literários da humanidade, "que não o havia incluído em seu anterior $O$ Cânone Ocidental, ausência justificada posteriormente pelo crítico americano pela falta de boas versões das obras do autor brasileiro para o inglês." Da mesma forma que a estética do exotismo influenciou tanto a produção como a recepção da literatura brasileira, a adoção do conceito de alegoria nacional como definição das obras produzidas nos chamados países do Terceiro Mundo poderia colocar estreitos limites à produção cultural de um vasto (lbidem: 166.)

(BLOOM, Harold. Gênio. Tradução de José Roberto O'Shea. Rio de Janeiro: Objetiva, 2003.)

" MOURA, Flávio. "Leio, logo existo. O mais polêmico dos críticos literários diz por que ainda se deve ler num mundo dominado pelas imagens". Entrevista. Revista Veja. São Paulo: Abril, 2003.) 
grupo de nações, excluindo de seu espectro toda produção que fugisse ao conceito, e marginalizando diferentes propostas literárias que existam ou possam surgir nessas literaturas, como certa crítica tentou fazer com Machado de Assis.

\section{Conclusão}

Será que na proposta de Ferdinand Denis e Fredric Jameson não podemos encontrar a mesma estratégia dos jesuítas de sistematização da língua geral, para estabelecer uma "unidade normativa, linguística e cultural indígena, para fundar uma possibilidade interpretativa [jesuítica] (ocidental)".* Estabelecer categorias estanques para a produção cultural do Brasil ou dos países menos desenvolvidos através de teorias poéticas não seria uma forma de "inscrição do outro", em que se busca apagar suas especificidades frente a uma categoria externa em nome de uma pretensa integração, quando na verdade se opera uma mitificação. Mitificação que, segundo Said,

É um discurso, ou seja, não pode ser senão sistemática; o discurso não é feito quando se quer, nem são feitas declaraçōes no seu interior sem que antes se pertença [...] à ideologia e às instituiçōes que garantem a sua existência. Estas últimas são sempre instituições de uma sociedade avançada que lida com outra menos avançada, de uma cultura forte que encontra outra mais fraca. A característica principal do discurso mítico é que ele oculta as próprias origens, bem com as origens daquele que ele descreve."

Desvendar as origens do discurso mítico e de seu objeto de descrição, através de uma leitura que Said chama de contrapontual, por levar em conta tanto o processo do imperialismo quanto o da resistência a ele, pode oferecer uma estratégia para entender como a tradução e a literatura de viagem vem ajudando na construção de uma imagem do Brasil, tanto para os estrangeiros como para os próprios brasileiros.

\section{Eduardo Luis Araújo de Oliveira Batista}

Doutorando em Teoria e História da Literatura, Unicamp. Visiting Research Assistant, Department of Spanish Studies, Queen Mary College, University of London, Londres, Reino Unido, no período de 08 de março a 30 de agosto de 2009. Mestre em Estudos Literários pela FALE/UFMG. Bacharel em Tradução da Língua Inglesa, ICHS/UFOP. Artigos publicados: O Modernismo brasileiro como literatura de exportação: a poesia modernista brasileira traduzida 
por Elizabeth Bishop. Travessias, v.2, p.17, 2008. Representação cultural brasileira no estrangeiro: a presença da literatura de viagem e das traduções nas relações culturais Brasil/EUA. MOARA, v. 25, p. 176-192, 2006. Poética da representação cultural - uma ponte conceitual entre a literatura de viagem e a tradução. Tradução e Comunicação., v.14, p. 17-36, 2005.

\section{Resumo}

As relações interculturais durante um longo período da história foram realizadas em sua maior parte pelos viajantes e tradutores. A partir do século XV a expansão colonial europeia utilizou-se das diversas representações sobre os povos subjugados e seus territórios, criadas por esses agentes, para construir um discurso colonial que buscava justificar e naturalizar o domínio europeu sobre suas colônias. Modernamente o trabalho desse corpo de funcionários foi substituído por, entre outros, o etnógrafo e o acadêmico, e o poder colonial foi substituído pelo neoimperialismo econômico e cultural. A violência implícita nessas representaçôes consiste basicamente em caracterizar uma suposta incapacidade de autogerência e desenvolvimento desses povos sem a tutela europeia, além de vincular a determinação de sua identidade cultural a um discurso eurocentrista. Neste trabalho apontamos como algumas dessas práticas se desenvolveram na história brasileira, demonstrando de que forma as representaçôes culturais sobre o outro podem trazer implicitamente um discurso de dominação.

\section{Abstract}

The relations between different cultures have been developed for a long time in cultural history by the correlated work of translators and travelers. Since the beginning of the fifteenth century, the representation of other peoples and cultures disseminated by these agents has been in service of the European colonial power in order to justify and naturalize its domination over its colonies. In modern ti-

\section{Résumé}

Les relations interculturelles sur une longue période de l'histoire ont été menées principalement par des voyageurs et des traducteurs. Depuis le XVe siècle, l'expansion coloniale européenne a profité de différentes représentations de peuples soumis et leurs territoires, crées par ces agents, pour construire un discours colonial qui a cherché à justifier et à naturaliser la domination européenne sur les colo-
Palavras-chave: tradução; literatura de viagem; representação cultural.
Key words: translation; travel literature; cultural representation.

Mots-clés: traduction; littérature de voyage; représentation culturelle. 
mes the work of academics and anthropologists has taken place as a legitimating discourse of economic and cultural neoimperialism. The implicit violence enclosed in the representations of other peoples provided by them consists basically in demonstrating their pretended incapacity of self-rule and development without European dominion. In this work we try to point out how some of those described cultural practices have been present in Brazilian history, disclosing in which ways cultural representations about other peoples can carry an implicit discourse of domination. nies. Dans les temps modernes le travail de ce corps de fonctionnaires a été remplacé par, entre autres, l'etnologue et chercheur, et le pouvoir colonial a été remplacé par le néo-impérialisme économique et culturel. La violence implicite dans ces représentations apparaît dans la caractérisation d'une soi-disant incapacité à l'auto-gestion et au développement de ces peuples sans la tutelle européenne, et aussi dans ce lien qui est établi entre la détermination de leur identité culturelle à un discours eurocentrique. L'objectif de cet étude était de montrer comment ces pratiques se sont développées dans l'histoire brésilienne, en soulignant comment les représentations culturelles de l'autre sont susceptibles d'introduire un discours implicite de la domination. 